TIILE: PILAC : A PION LINAC FACILTYY FOR 1 GEV PION PHYYSICS AT IAMPF

AISIIIOR(S): HENRY A. THIESSEN

LOS AI AMOS NA'TIONAI. LABORA'TORY

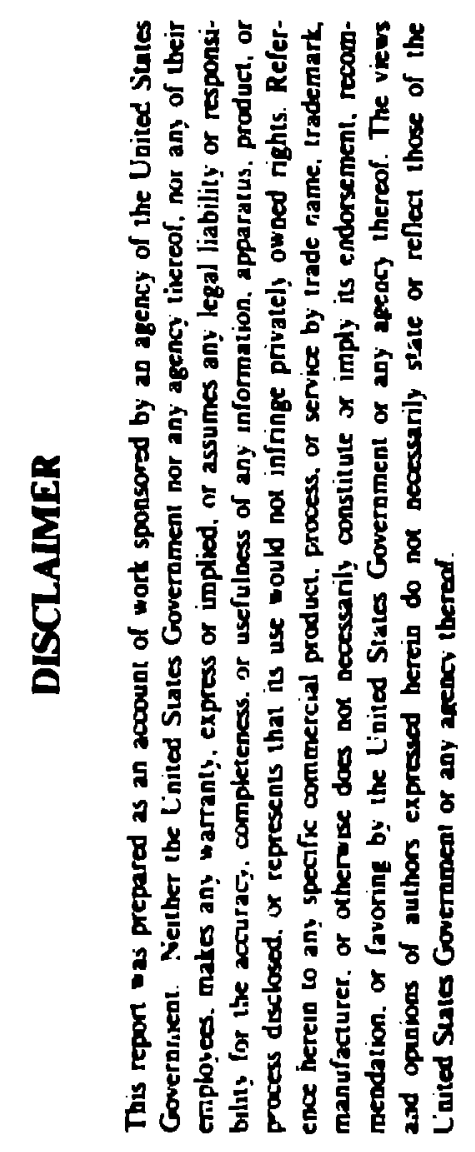

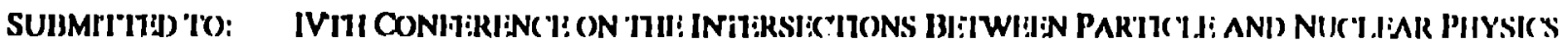
MAY 24-29, 1991

'TKSON, ARIZONA

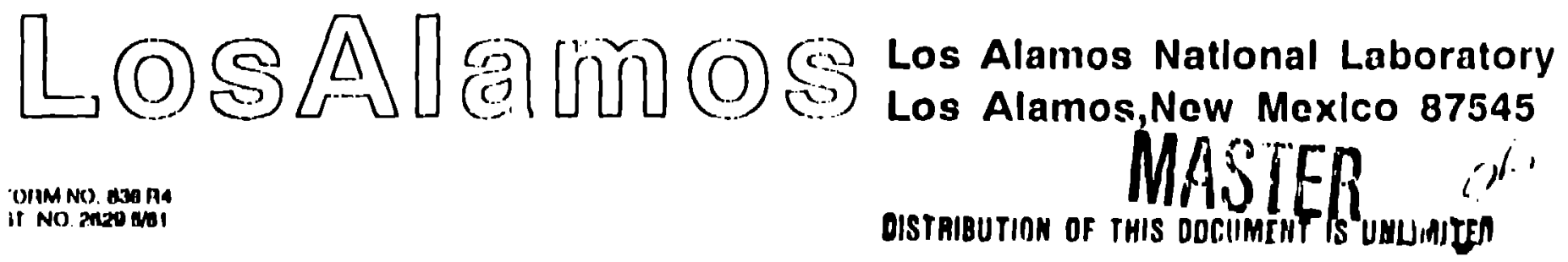




\title{
PILAC: A Pion Linac Facility \\ for 1-GeV Pion Physics at LAMPF
}

\author{
Henry A. Thiessen \\ Los Alamos National Laboralory \\ Mail Stop H-847 \\ Los Alamos, New Mexico 87545
}

\begin{abstract}
Abstraci
A design study for a Pion Linac (FILAC) at LAMPF is underway at Los Alamos. We present here a reference design for a system of piun source, linac, and high-resolution beam line and spectrometer that will provide $10^{\circ}$ pions per second on target and $200-k e V$ resolution for the $\left(\pi^{+}, \mathrm{K}^{*}\right)$ reaction at $0.92 \mathrm{GeV}$. A general-purpose beam line that delivers both positive and negative pions in the energy range $0.4-1.1 \mathrm{GeV}$ is included, thus opening up the possibility of a broad experimental program as is discussed in this report. A kicker-based beam sharing system allows delivery of beam to both beamlines simultaneously with independent sign and energy con'rol. Because the pion linac acts like an rf particle separator, all beams produced by PILAC will be free of electron (or positron) and proton contamination.
\end{abstract}

\section{I. 'Tue Nuctrar Puysics Program of PIlac}

There are five classes of experiments that require pions of energies up to $1.1 \mathrm{GcV}$ [1]. These clnsses are:

1.) $\Lambda$-hyjecnuclehr physics $4 . .1$ the $(\pi, K)$ reaction;

2.) $\Lambda$-nucleon senttering at threshold;

3.) rare decays of $\pi$ and 1 ;

4.) pion-nucleus clastic and inelastic scatter-

ing with 0.4-1.1 GeV piors; and

5.) baryon resonances.

\section{PILAC CONCIIII}

A concept for the reference facility is shown In Figure 1. The reference Pll AC: fncilliy re. quires the following items [2]:

1.) proton buticher:

2.) new tnrget cell for zero-degrec pion procluctions:

1.) 11.38 .0 .53 - (ie: $V$ pion injertion locnmuline;

1.) (1.38-0.92-(ic. V, 12..5 Mr.V/m prindient suprecomducting pion linatr;

5.) klcker-lonsed benm - sharing sysiem;

(.)) 1.1 - (ieV high-resulullon dispersed lienm line ni el spectromeler:

7.) general-purpose lornm Jine with dlspersed

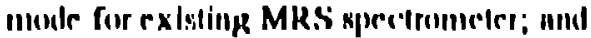

H.) experimential nren and relunted civil renpincerrlup.

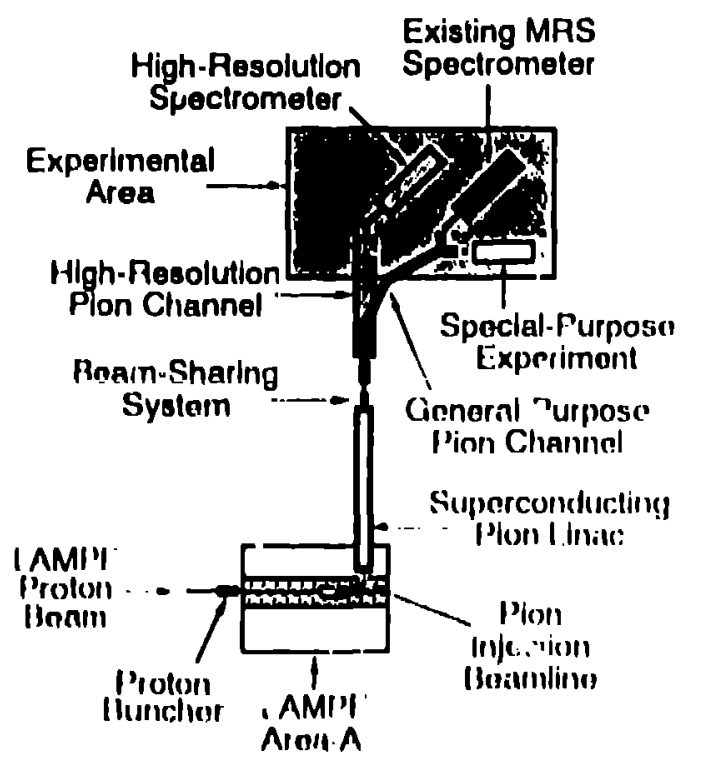

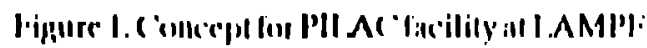




\section{Proposiin Diivilopmint Pian lor Surterconiducitang Cavimis for !ILAC}

The reference design requires $12.5 \mathrm{MeV} / \mathrm{m}$ cavily gradient and has negligible beam loading. We believe that this large gradient can best be achieved by use of titanium heat-treated niobium cavities [3]. In order to establish the gradient and $Q$ that will be achieved in the PILAC cavilies, it is necessary to scale up the technology to the larger, lower-frequency cavilies needed and to test several prototype cavities. This requires new, larger facilities at Los Alamos. To save time, we propose to develop the heal-treatment technology in a parallel effort using existing equipment at $3 \mathrm{GlHz}$. We will also take an existing 805-MIz single-cell cavily and heat-Ireat it in the Cornell oven.

\section{INJLiCTTON BLLM LINI:}

The injection beam line proposed for PILAC consists of a matching section based on a strong quadrupole doublet placed as close as possible to the pion-production targel followed by a second-order achroniat. Sextupoles and octupoles correct all detrimental second- and hird-order aberrations. This beam line has a solid angle of $10 \mathrm{msr}$, a momentum acceptance of $6.6 \%$, and a transverse phase-space output of $225 \pi \mathrm{mm}$-mrad. In the reference version of this beam line design, $82 \%$ of tl:e outpul beam is contained within the specified phase space.

We are also considering a possible design of the injection beam line that will deliver both $\pi^{*}$ alld $\pi^{*}$ simultaneously s is shewn in Figure 2 . This version of the injection line has nol yet been studied thoroughly.

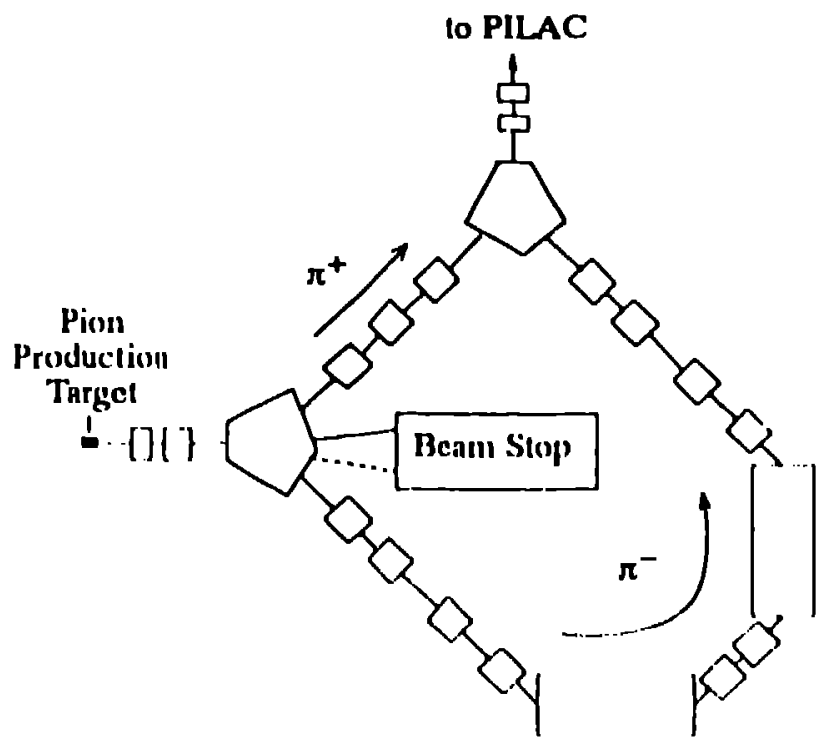

lijpure 2. P'ossible deslygn for simultumeons $\pi^{\circ}$ ind $\pi$ injerclion lint for lil $A C$ :

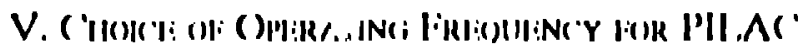

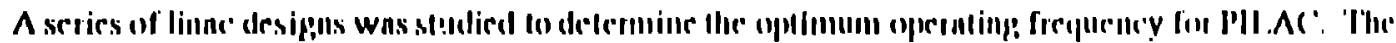

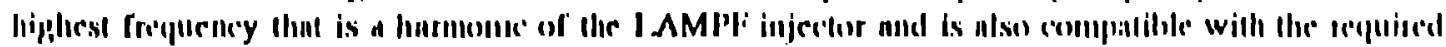

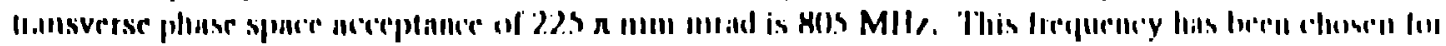
hie relierenese desigyt. 


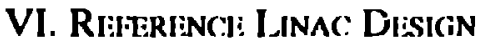

The reference linac design is based on a study maximizing the pion intensity in the desired output phase space. A conceptual layout of this design is shown in Figure 3. Thic beam intensity is the product of longitudinal acceptance and pion survival in the linac. $\Lambda$ tolal phase space rotation of $3 r / 4$ in the longiludiual plane maximizes the acceptancewhile minimizing the energy spread of the output bcam. The layout of the linac minimizes pion decay. The number of celis per cavily was chosen to give the largest cavity that can be handled comfortably in the existing superconducting cavity lab. This results in a choice of seven cells per cavity. A total of 40 cavities is required to accelernte from $0.38-0.92 \mathrm{GeV}$. By raising the injection energy and rephasing the linac, energies up to $1.1 \mathrm{GeV}$ can be provided, but at reduced intensity. Quadrupole doublets are required after each five cavitics in order to contain the transverse phase space in the cavily bort. Five cavities will be mounted in a single cryostal as a module. Eight modules are combined to make the full linac. The tolal length of the linac is approximately 90 meters.

\section{5-MHz PILAC: 380 to 920 MeV K.E.} (Fast synchrotron oscillation)

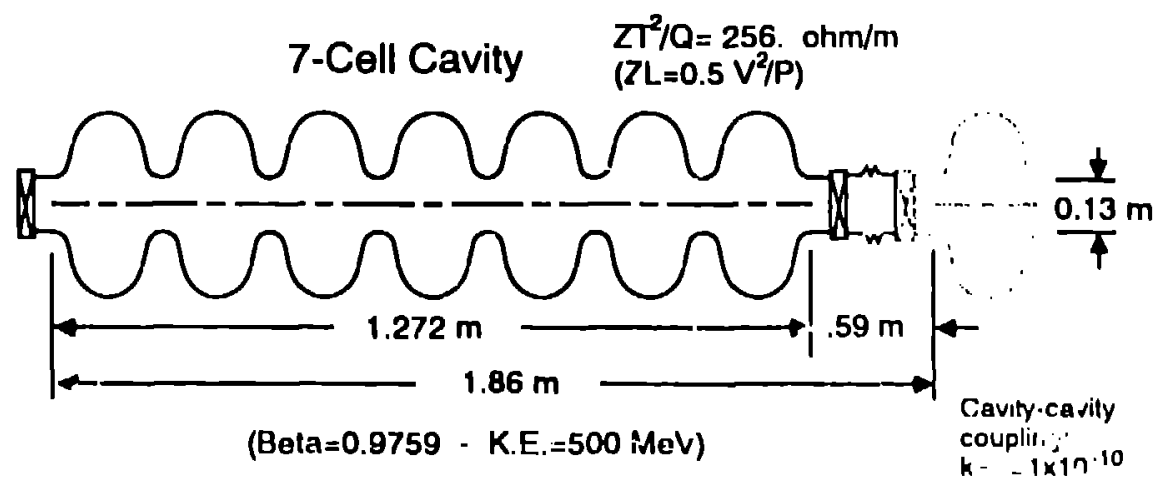

Cryostat With 5 Cavities

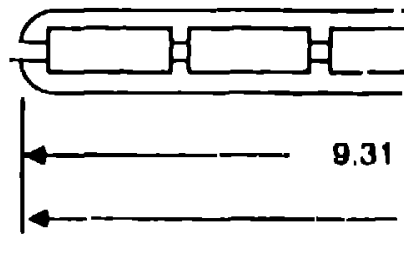

(E:/pi-2.25 mm-mi unnor. at linfice ontrance)
Quad Doublet

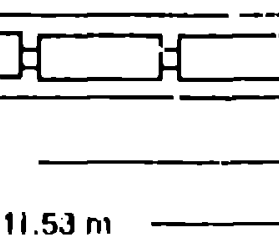

Polo tip 13 (1) 35,

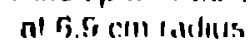

Pion Linac: 8 Cryostat Units

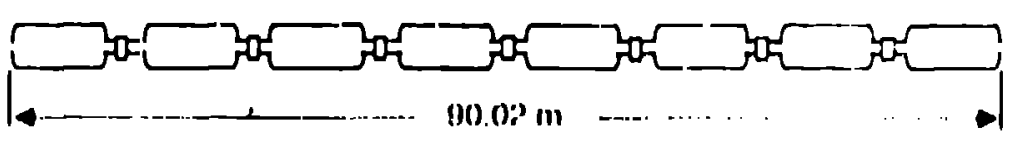

kHtal actlve Innglh: 40 cavilins $\times 1.2 / 2$ - 50 HII m

I0) :- I:Ali MoV/In

Sinvival fenctionl 11 (i",

Mns inis

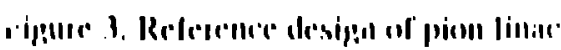




\section{HIGII-RI:SOI.UT1ON BI:AM LINI: AND SHIICTROMI:II:R}

A high-resolution beam line has been designed using program MOTER [4]. This heam line, a QQQQMDMDMUMDM design with vertical bends, his a momentum dispersion of $25 \mathrm{~cm} / \%$ alld a horizontal divergence of 5 nurad full width in the horizontal planeand is shown in Figure 4. The full size of the bean spot will be $40-\mathrm{cm}$ high by $10-\mathrm{cm}$ wide. The momentum resolution of the high-resolution beam line calculated by MOTER is one part in $10^{4}$ whe. second- and third-order optical corrections are introduced on the dipole entrance and exit faces.

\section{PILAC High-Resolution Beam Line QQQQMDMDMDMDM MOTER OUTPUT}

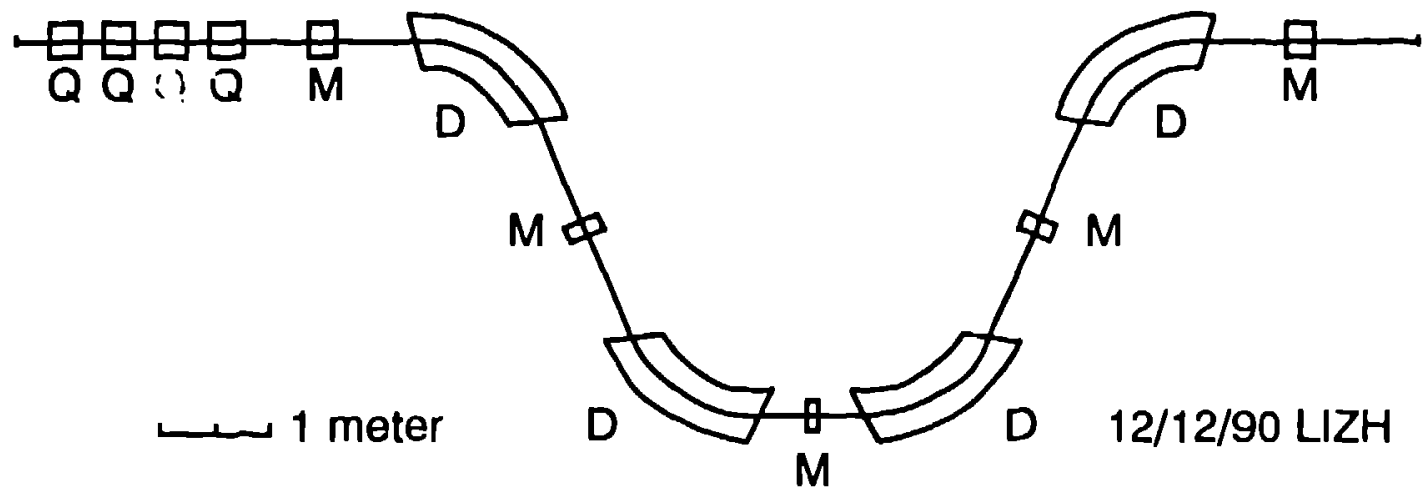

lïguc 4. High rẹsolution beam line for Pll AC.

A spec : rometer with acceptance matched to th is beam line has also been designed and is show in in ligure 5. The design is very similar to that of the existing I:PICS spiectrometer at I AMPF except that the loending magnet has been made from a slugle unit in order lo minimize the night path of kaons in the spectrometer. By using iron-dominated superconducting quadrupole magnets similar (o lhose planned for the Hall-(" spectrometer at CLBBAl, the arceptance of the spectrometer has bern increased hy almost a factor of six compared with that of the existing LiPICS spectrometer. ITie ncereptance of the proposed spectrometer is 27 millisteradians for the 10 -('m $\times$ 40)-('m beam size of the high-resolution loram line.

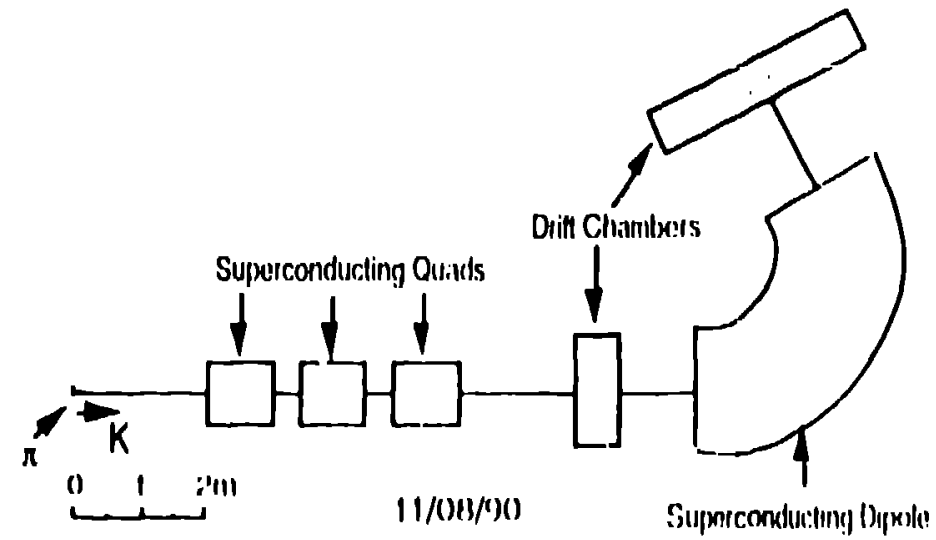

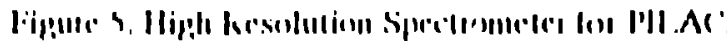




\section{Ginitral-Purpose Biam Lini:}

A beam line capable of providing an achromatic beam spot and also $2-3 \mathrm{~cm} / \%$ horizontal dispersion (for use with the existing MRS spectrometer) is being designed. The output beam spot and divergence in the achromatic mode will be $5-\mathrm{mm}$ radius by 25 mrad (half widths). The output beam spot will be tuneable over a wide range. We are also studying a second port for the output of this line. In addition to providing beam for experimenters, the new general-purpose line will serve as a pion injector for a future linac extending the energy range of PILAC to $1600 \mathrm{MeV}$.

\section{BEam SHaringi in PILAC}

A kicker-based beam sharing system is envisaged for PILAC. With the kicker magnet off, the pion beam from the linac goes straight ahead into the high-resolution beam line. With kicker magnet on, the beam is deflected into the general-purpose line. The basic idea is that the kicker rise time will be comparable to the time required to switch the phase program of the linac cavities. Then the phase program and the kicker can be switched simultaneously. With simultaneous injection of $\pi^{+}$and $\pi$ into the linac, it will be possible: to have independent control of the pion sign and energy delivered to each of the two beam lines.

\section{PILAC PION YIHID}

The pion yield expected from PILAC is $1.2 \pm 0.6 \times 10^{\circ} \pi^{\circ}$ per second at $0.92 \mathrm{GeV}$. This yield is comparable to that which can be achieved in the same phase space at the proposed KAON facility and is more than an order-of-magnitude larger than can be achieved at the Brookhaven AGS with the new booster operating, as is sliown in Figure 6. In this figure, the yield of PILAC is shown as a function of the cavity gradient. A design value of $12.5 \mathrm{MeV} / \mathrm{m}$ has been chosen for the Reference Design.

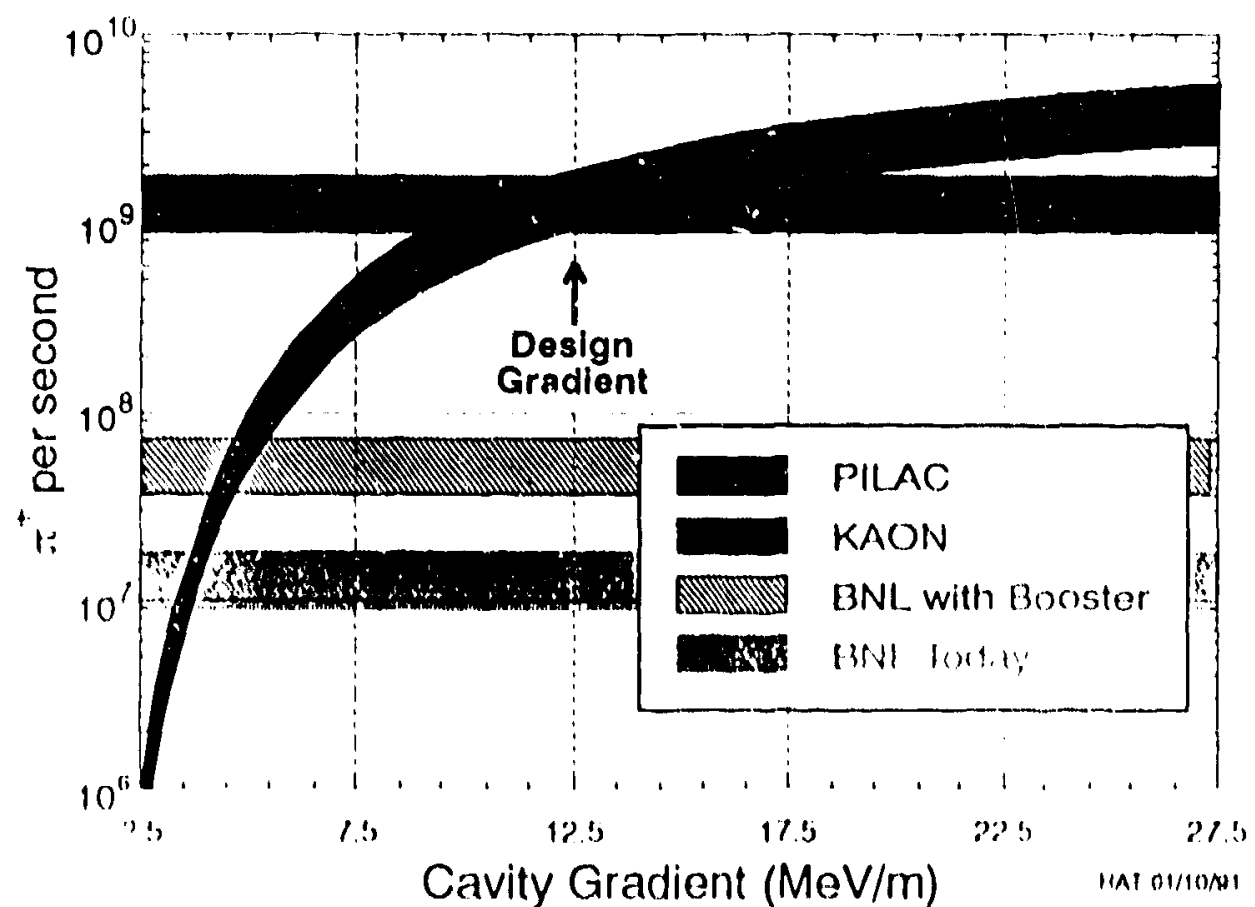

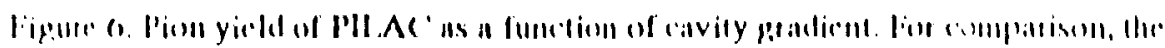

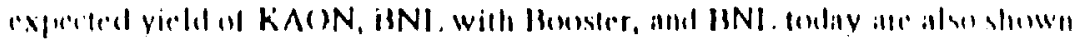




\section{Progiram MOTER}

The program used for raytracing calculations of the high-resolution beam line and speclrometcr is MOTER (Morris Klcin's Optimized Tracing of Enge's rays). This program was wrillell at Los Alamos in the early 1970s [4]. MOTER is being updaied in include if cavities in order to make possible a precision sludy of the optics of PILAC in a single computer program.

\section{Summary and Conc'lusions}

PILAC is being designed to provide a benm of $10^{\circ}$ pions per second at $0.92 \mathrm{GeV}$, with a future upgrade to $1.6 \mathrm{GeV}$. We have Jemonstrated that the system resolution of $200 \mathrm{keV}$ can be achieved in a highresolution beam line and spectrometer. In order to provide the necessary flux, the linac requires superconducting cavities that achicve a gradient of $12.5 \mathrm{MeV} /$ meter. Although no linac presently operales at this high gradient, tests at laboratories ari und the world have show'n that this gradient can be achieved by titanium heal treatment of the cavities. As R\&D program is proposed to scale up the results from singlecell 1.5-3-GHz cavitics to the necessary 7-cell 805-MHz cavities.

PILAC will provide an energy of $0.92 \mathrm{GeV}$ with operation possible up $101.1 \mathrm{GeV}$ at reduced intensity. This energy is sufficient to optimize the yield of the $\left(\pi^{*}, \mathrm{~K}^{+}\right)$reaction and 10 access a broad range of interesting physics. The PILAC energy resolution, $200 \mathrm{keV}$, is more than an order-of-magnitude belter than that which is available today and will give uccess to a wealth of information on hypernuclear physics. The PILAC beam-sharing system will allow simultaneous operation of two or more line with independent sign and energy control. The PILAC benms will be of unprecedented purity since the linac acts as a highresolution rf scparator. PILAC is cost-effective since it is by far the least expensive upgrade to LAMPF that gives access to this physics. The new superconducting cavitics represent a new technology that will open up applications in other ficids. Finally, PII AC is feasible only at LAMP!: since only LAMPF has the necessary tightly bunched proton beam to produce pions that can then be accelerated in a superconducting linac.

\section{RHIIIRINACIS}

[1] "Physics with PILAC," Los Alamos Rejort, on be published.

12] PILAC Technical Notes 1-25, L.0s Alamos, 1')(X).91 and ofher contributions (o) lhis conference.

[3] II. Padimsce, IFili: Cat. No 87C:I12.387-9, 1691 (1987).

[4] II. A. Thiessen and M. M. Klein, Proxecedings of the 4th International Confierence on Mngnet Techunology, Brookhnven, N.Y., pp 8-17 (1072). 